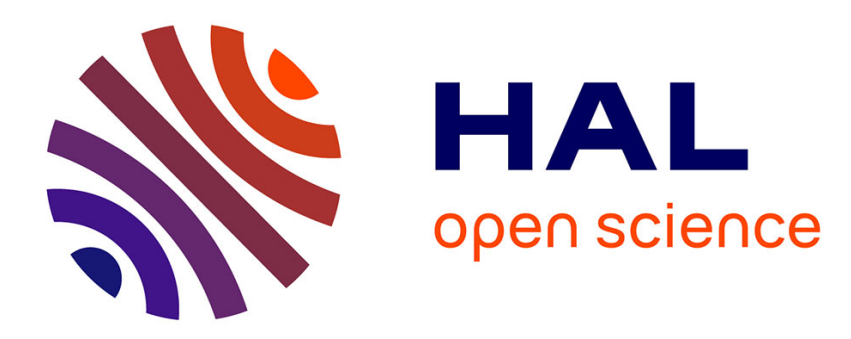

\title{
Failure micromechanisms in particulate-reinforced metal-matrix composites
}

\author{
J. Llorca
}

\section{To cite this version:}

J. Llorca. Failure micromechanisms in particulate-reinforced metal-matrix composites. Journal de Physique IV Proceedings, 1993, 03 (C7), pp.C7-1793-C7-1798. 10.1051/jp4:19937284 . jpa-00251926

\section{HAL Id: jpa-00251926 https://hal.science/jpa-00251926}

Submitted on 1 Jan 1993

HAL is a multi-disciplinary open access archive for the deposit and dissemination of scientific research documents, whether they are published or not. The documents may come from teaching and research institutions in France or abroad, or from public or private research centers.
L'archive ouverte pluridisciplinaire HAL, est destinée au dépôt et à la diffusion de documents scientifiques de niveau recherche, publiés ou non, émanant des établissements d'enseignement et de recherche français ou étrangers, des laboratoires publics ou privés. 


\title{
Failure micromechanisms in particulate-reinforced metal-matrix composites
}

\author{
J. LLORCA
}

\author{
Department of Materials Science, Polytechnic University of Madrid, E.T.S. Ingenieros de Caminos, \\ 28040 Madrid, Spain
}

\begin{abstract}
The failure micromechanisms in tension and fracture were evaluated in a $2618 \mathrm{Al}$ alloy reinforced with 15 vol. \% SiC particulates with the help of quantitative microscopy. It was concluded that failure was due to the progressive fracture of the ceramic reinforcements during deformation, and that $\mathrm{SiC}$ particulates of larger size and elongated shape were more prone to fail than small, equiaxed ones.

\section{INTRODUCTION}

Particulate-reinforced metal-matrix composites (MMC) are usually made up of a light alloy ( $\mathrm{Al}$ or $\mathrm{Mg}$ ) reinforced with high-modulus ceramic particulates, such as $\mathrm{Al}_{2} \mathrm{O}_{3}$ or SiC. They present better stiffness, strength, wear resistance and, in many cases, fatigue crack growth resistance than the corresponding unreinforced alloys. Additional advantages include the ability to be processed and machined by procedures similar to those employed for the monolithic alloys. However, their use in engineering applications is hindered by their limited ductility and fracture toughness, so it is not surprising that the failure micromechanisms have been the object of research activity to ascertain the causes of composite failure and devise strategies to enhance these properties. The problem is not an easy one, and the results have shown the dependence of the failure micromechanisms on several factors, such as the manufacturing route [1] and thermo-mechanical treatments [1-2]. In fact, these investigations have pointed out that detailed studies are required for each particular material in order to determine the specific changes that should be introduced during fabrication to improve ductility and fracture toughness.

This paper studies the failure micromechanisms of a spray formed $2618 \mathrm{Al}$ alloy reinforced with $15 \mathrm{vol}$. \% SiC particulates. Tensile tests at ambient temperature as well as fracture toughness tests in the temperature range $-136^{\circ} \mathrm{C}$ to $190^{\circ} \mathrm{C}$ were carried out. The broken samples were carefully examined by optical and scanning electron microscopy to determine the failure processes. The experimental results are discussed, and several recomendations to improve the ductility are provided.
\end{abstract}

\section{MATERIALS AND EXPERIMENTAL TECHNIQUES}

A spray formed $2618 \mathrm{Al}$ alloy reinforced with 15 vol. \% of $\mathrm{SiC}$ particulates was used in this investigation. The material was supplied by Cospray (UK) in the form of extruded rectangular bars (cross section $25.4 \mathrm{~mm} \times 62.5 \mathrm{~mm}$ ). After extrusion, the bars were solution heat treated at $530^{\circ} \mathrm{C}$ for 1 hour, water quenched, and cold stretched up to $2 \%$ to relieve the residual stresses introduced by quenching. Afterwards, they were artificially aged at $190^{\circ} \mathrm{C}$ during 10 hours to reach the peak-aged condition (T651), and tensile and fracture toughness specimens were machined from the bars. Several tensile specimens were then solution heat treated $\left(1\right.$ hour at $\left.530^{\circ} \mathrm{C}\right)$ to erase the effect of the prior thermo-mechanical treatments, quenched in water, and naturally aged at room temperature (T4).

The microstructural features in both tempers had been previously studied [3]. The grains were equiaxed, with an the average grain size of $15 \mu \mathrm{m}$. Rounded inclusions, with an average size around $3 \mu \mathrm{m}$, were distributed within the Al alloy grains, at the grain boundaries, and at 
the $\mathrm{SiC}$ interfaces (Fig. 1a). Energy dispersive $\mathrm{X}$-ray microanalysis found the presence of $\mathrm{Al}, \mathrm{Fe}$ and $\mathrm{Ni}$. More detailed studies by X-ray diffraction confirmed that the inclusions were made up of a monoclinic $\mathrm{Al}_{9} \mathrm{NiFe}$ intermetallic. The distribution and size of the inclusions was the same in both T4 and T651 conditions. Transmission electron microscopy studies detected the presence of S and $\mathrm{S}^{\prime}$ precipitates $\left(\mathrm{Al}_{2} \mathrm{CuMg}\right)$ in the peak-aged condition but not in the naturally aged material. The S' precipitates were distributed throughout the matrix, and no precipitate free zones were observed. The S precipitates, on the other hand, were found mainly at the grain boundaries and at $\mathrm{SiC}$ interfaces as well as at the $\mathrm{Al}_{9} \mathrm{NiFe} /$ matrix interfaces (Fig. 1b). Optical micrographs taken from polished sections of the composite in the extrusion direction indicated that only $2 \%$ of the particulates were broken prior to testing. Most of the particulates were oriented with their longer axis in the extrusion direction.
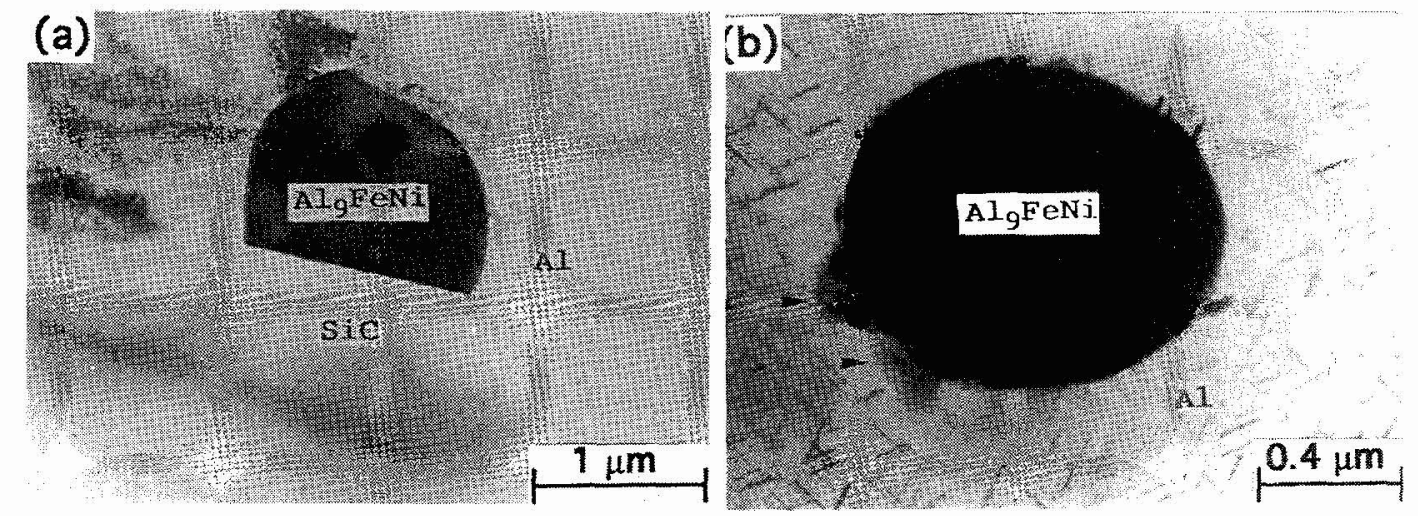

Figure 1. (a) Transmission electron micrograph of the composite in the $\mathrm{T} 4$ temper showing an $\mathrm{Al}_{9} \mathrm{NiFe}$ intermetallic particle at the $\mathrm{SiC} /$ matrix interface. (b) Precipitation in the T6 temper. S' precipitates with a lath shape are distributed throughout the matrix. S precipitates (marked with arrows) are observed at the particle/matrix interface.

Tensile tests at an average strain rate of $10^{-4} \mathrm{sec}^{-1}$ were carried out for each temper in the extrusion direction. Compact tension specimens (thickness $25.4 \mathrm{~mm}$ ) in the peak-aged condition were employed for the fracture tests, the crack being oriented in the L-T direction. After fatigue precracking, the fracture tests were performed in stroke control, and the displacement rate was set to obtain a stress intensity factor rate of $0.6 \mathrm{MPa} \sqrt{\mathrm{m}} / \mathrm{s}$. For elevated and low temperature fracture tests, the specimen was placed in a temperature chamber. Heating was achieved with the help of an electric resistance, and liquid nitrogen was used for cooling. The specimen temperature was measured with a K-type thermocouple, introduced into a $2 \mathrm{~mm}$ deep hole machined in the specimen. Heating (or cooling) rate was always lower than $5^{\circ} \mathrm{C}$ per minute. The specimen was held during 20 minutes at the test temperature $\left( \pm 2^{0} \mathrm{C}\right)$ prior to testing, to ensure a homogeneous temperature distribution through the thickness.

Once broken, tensile and fracture specimens were sliced through the middle with a diamond saw and polished on SiC abrasive paper to 600 grit finish. This was followed by polishing on an $\alpha$-alumina $(0.3 \mu \mathrm{m})$ slurry, and finally on magnesia. The polished samples were first cleaned in deionized water, and afterwards by ultrasound in acetone. Optical and scanning electron microscope micrographs were taken from the polished surfaces at less than $4 \mathrm{~mm}$ from the fracture surface in the tensile specimens, and just below in the fracture specimens. The micrographs were studied by means of a computer-controlled image analysis system to determine the number, area, and aspect ratio of broken and intact particulates. In addition, the fracture surfaces were examined by scanning electron microscopy to ascertain the main failure mechanisms for each heat treatment, and temperature.

\section{RESULTS}

The ambient temperature mechanical properties are given in Table 1 , and the evolution of the fracture toughness with the temperature in the peak-aged condition is shown in Fig. 2 . The composite fracture surfaces exhibited microscopically a ductile appearance (Fig. 3). SiC particulates were present in the fracture surfaces in both T651 and T4 conditions. Smaller voids around the intermetallic inclusions were also seen, specially in the T4 temper. The matrix was heavily 
deformed around the particulates and no interfacial debonding was seen. The fracture surfaces in the specimens tested at low and elevated temperatures exhibited the same features, and no significant influence of the temperature on the fracture surfaces was observed.

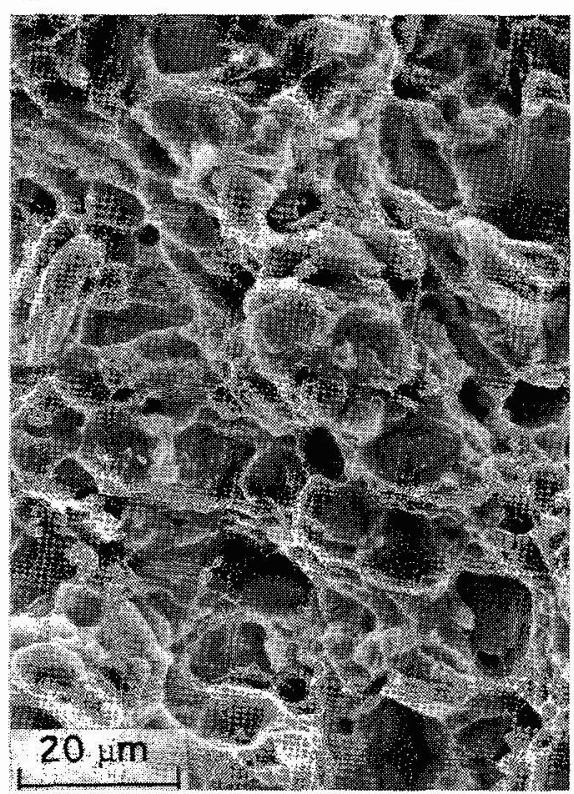

Figure 2. Fracture surface of the composite material in the T651 temper.

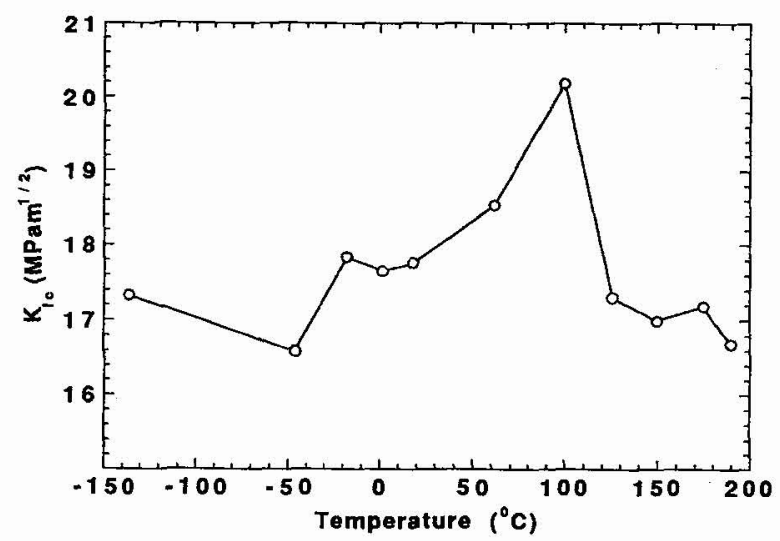

Figure 3. Influence of the temperature on $K_{I c}$ in the T651 temper.

TABLE 1. Ambient Temperature Tensile Properties

$\begin{array}{ccccc}\text { Temper } & \begin{array}{c}E \\ (\mathrm{GPa})\end{array} & \begin{array}{c}\sigma_{y} \\ (\mathrm{MPa})\end{array} & \begin{array}{c}\sigma_{u} \\ (\mathrm{MPa})\end{array} & \begin{array}{c}\epsilon_{u} \\ (\%)\end{array} \\ \mathrm{T} 4 & 94 & 254 & 482 & 12.3 \\ \mathrm{~T} 651 & 95 & 484 & 503 & 4.1\end{array}$

The tensile specimens were sliced through the middle after failure, polished, and observed in the microscope to evaluate the micromechanisms of fracture in the loading direction near to and far away from the fracture surface. A number of particulates were fractured (Fig. 4) in both tempers, the cracks being oriented perpendicularly to the loading axis. Broken particulates were seen throughout the gage length. The $\mathrm{SiC}$ reinforcements and the intermetallic inclusions (which can be recognized in Fig. 4 by their smaller size and rounded shape) were well bonded to the matrix. The damage was concentrated on the $\mathrm{SiC}$ reinforcements, whereas no broken inclusions were seen far away from the fracture surface. The fraction of broken $\mathrm{SiC}$ particulates was $19.6 \%$ in the T651 temper and $18.1 \%$ in the T4 temper. The values for the specimens tested in fracture at different temperatures are given in Table 2.

TABLE 2. Fraction of broken SiC particulates, $N^{b}$, just below the fracture surface in the specimens tested in fracture at various temperatures

$$
\begin{array}{ccccc}
\text { Temperature } & -136^{\circ} \mathrm{C} & 18^{\circ} \mathrm{C} & 100^{\circ} \mathrm{C} & 190^{\circ} \mathrm{C} \\
N^{b} & 11 \% & 14 \% & 10 \% & 15 \%
\end{array}
$$

A statistical study was carried out of the geometric characteristics (average area, $A$, maximum $\left(D_{\max }\right)$ and minimum $\left(D_{\min }\right)$ diameters, and aspect ratio, $\left.D_{\min } / D_{\max }\right)$ of broken and intact $\mathrm{SiC}$ 


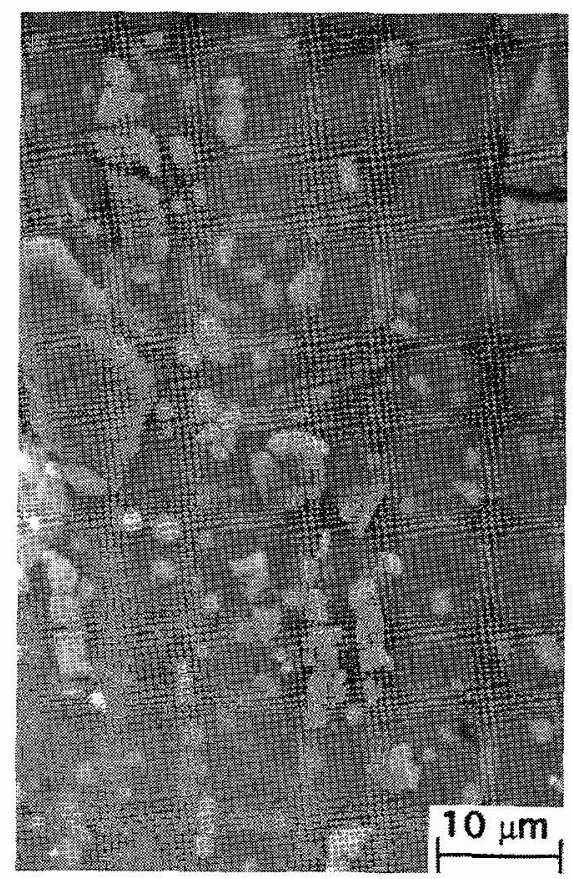

Figure 4. Fractured $\mathrm{SiC}$ particulates $3 \mathrm{~mm}$ below the fracture surface for the composite tested in the T651 temper. The cracks in the particulates were oriented perpendicularly to the loading axis (vertical). It is worth noting that no intermetallic inclusions (recognized by their smaller size and rounded shape) were broken far away from the fracture surface.

particulates. The results are shown in Figs. 5 and 6 for the specimens tested in tension, where the fraction of broken particulates is plotted as a function of the square root of the area, $D$, and of the aspect ratio, respectively. Also included in these graphs are the total number of particulates studied (including broken and intact ones) for each size and aspect ratio. The results in Figure $5 \mathrm{a}$ and $5 \mathrm{~b}$ indicate that particulates with an average size smaller than $4 \mu \mathrm{m}$ were never broken, and those in excess of $17 \mu \mathrm{m}$, on the contrary, were always broken. The oscillations in the fraction of broken particulates found in the sizes between 10 to $15 \mu \mathrm{m}$ were due to the small number of particulates taken into account, which limits the accuracy of the statistical analysis. Figs. 6a and $6 \mathrm{~b}$ show that the fraction of broken particulates decreased monotonically as the aspect ratio increased (more spherical shape). On the other hand, around $60 \%$ of the particulates with an aspect ratio equal to 0.2 failed during deformation. The average values of $A, D_{\max }, D_{\min }$, and aspect ratio for the broken $\mathrm{SiC}$ particulates in the specimens tested in fracture at various tempe-
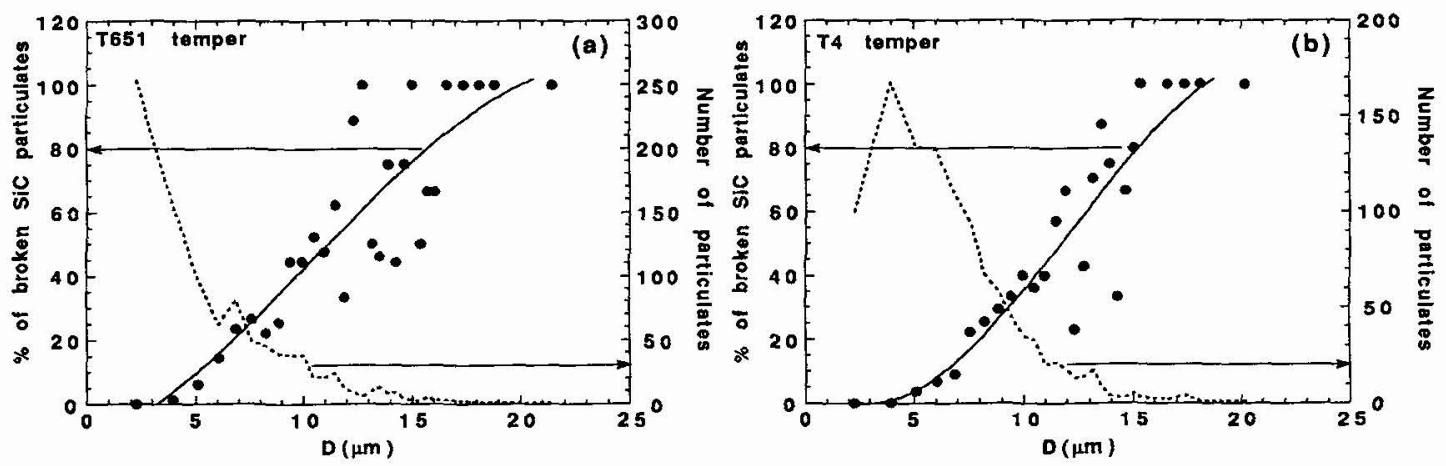

Figure 5. Fraction of broken $\mathrm{SiC}$ particulates as a function of the particulate size $D=\sqrt{A}$. (a) T651 temper. (b) T4 temper. 
ratures are shown in Table 3. Also included in this table are the values for the total number of particulates studied, including broken and non-broken. The trends observed in the tensile specimens were mantained in those tested in fracture, regardless of the test temperature.
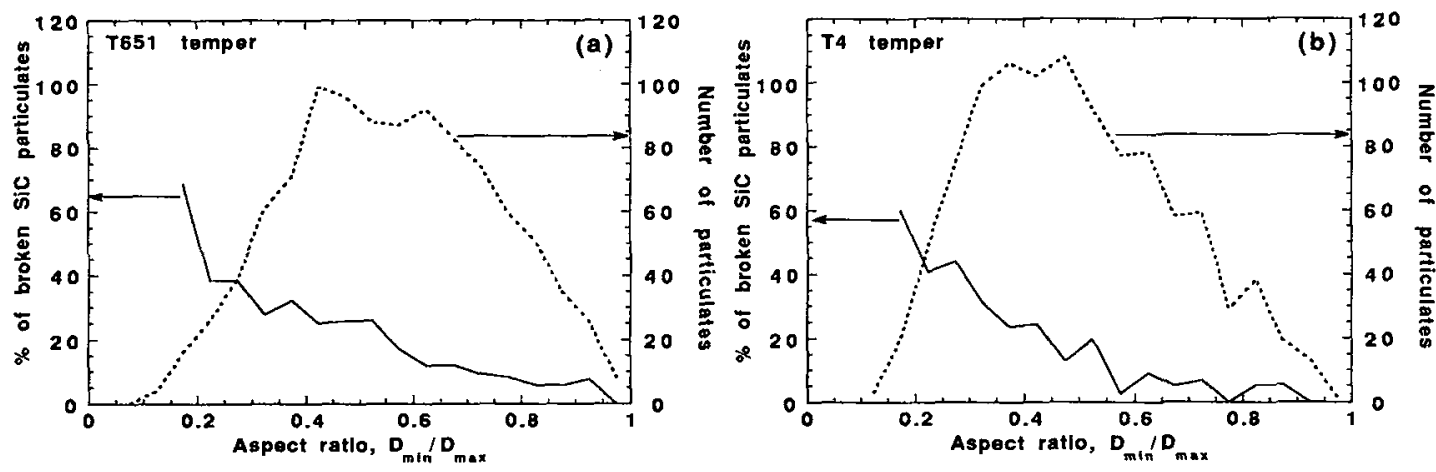

Figure 6. Fraction of broken $\mathrm{SiC}$ particulates as a function of the particulate aspect ratio, $D_{\text {min }} / D_{\text {max }}$. (a) T651 temper. (b) T4 temper.

TABLE 3. Geometric characteristics of broken and total (broken and non-broken) particulates just below the fracture surface in the specimens tested in fracture at various temperatures

\begin{tabular}{|c|c|c|c|c|}
\hline & $\begin{array}{c}A \\
\left(\mu \mathrm{m}^{2}\right)\end{array}$ & $\begin{array}{c}D_{\max } \pm \mathrm{SD} \\
(\mu \mathrm{m})\end{array}$ & $\begin{array}{c}D_{\min } \pm \mathrm{SD} \\
(\mu \mathrm{m})\end{array}$ & Aspect Ratio \pm \\
\hline & 90 & & & \\
\hline & 55 & 10.6 & $5.4 \pm 3.0$ & \\
\hline
\end{tabular}

\section{DISCUSSION}

The experimental observations reported above clearly indicate that particulate fracture played a key role in the tensile ductility of this composite. This had already been reported for other particulate-reinforced MMC tested under monotonic [3-6] and fully-reversed cyclic loading [7]. Measurements of the degradation of the Young's modulus during deformation have indicated that particulate fracture takes place progressively during deformation, as the load transferred from the matrix increases, until a critical volume fraction of particulates is broken, leading to specimen failure [3-4]. The results presented here provide additional information about the influence of the geometric characteristics of the reinforcement on its fracture probability. The analysis of the broken particulate size led to the conclusion that a size effect on the reinforcement fracture stress does exist. Large particulates are thus harmful to the composite tensile ductility, and they should be eliminated during processing, perhaps by sieving. On the other hand, particulates below 5 $\mu \mathrm{m}$ were rarely fractured. The probability of fracture increased rapidly with size (approximately with $D^{3}$ ), reaching $50 \%$ for a size of $10 \mu \mathrm{m}$. Although these probabilities depend on the matrix strength and on the far-field applied strain, the results clearly demonstrate the beneficial effects of reducing the average particulate size. Preliminary studies [3] indicated that the probability of fracture follows the Weibull statistics, and that the Weibull modulus of the particulates is close to 1.

Another finding of the statistical study is that elongated particulates oriented in the loading direction tend to fail earlier during deformation, because they carry more load. On the other hand, the composite modulus increases as the aspect ratio of the reinforcement decreases (more elongated particulates), and it is well known that whisker-reinforced MMC exhibit better elastic properties than particulate-reinforced MMC for the same volume fraction of reinforcement [8]. Thus it might be thought that high-strength defect-free, elongated whiskers oriented in the loading direction could be used as reinforcement to improve the ductility of metal-matrix composites. However, the 
experimental results do not show that whisker-reinforced MMC exhibit better ductility than those reinforced with particulates [8]. This is because the mechanism controlling ductility in whiskerreinforced $\mathrm{MMC}$ is the nucleation of cavities around the whisker ends and not whisker fracture [7, 9]. In the composite tested here, where interfacial failure was never seen, the presence of elongated $\mathrm{SiC}$ particulates has two main consequences. On the one hand, the Young's modulus is improved because the load transfer is more efficient. On the other hand, elongated particulates attain their fracture stress earlier, reducing the overall ductility of the composite.

The dominant failure mechanism during fracture testing in the whole temperature range was also particulate fracture, as indicated by the observations on the fracture and lateral surfaces. The analysis of the geometric features of the particulates broken in the fracture tests led to the same results as in tension: the probability of fracture increased with $A$ and decreased with $D_{\min } / D_{\max }$. Previous attempts [10-11] to model the fracture behaviour of particulate-reinforced MMC have emphasized the influence on $K_{I c}$ of the interparticulate distance and of the volume fraction of reinforcement. Our experimental observations point out that the geometric characteristics of the particulates, and specially the size distribution, are also very important parameters which could influence strongly the overall fracture properties.

\section{CONCLUSIONS}

The failure mechanisms in tension and fracture in a spray formed $2618 \mathrm{Al}$ alloy reinforced with 15 vol. \% SiC particulates were studied. The results indicated that the dominant failure micromechanism was particulate fracture, regardless of the heat treatment (either naturally aged or peak-aged) and the temperature (in the range $-136^{\circ} \mathrm{C}$ to $190^{\circ} \mathrm{C}$ ). The fracture probability of the reinforcement increased with the $\mathrm{SiC}$ particulate size, and elongated particulates oriented in the loading direction were more prone to fail than equiaxed ones. Thus, an improvement in the tensile ductilty is expected if the largest particulates are eliminated during processing, perhaps by sieving.

\section{Acknowledgements}

This research was supported by the European Community through contract BREU-075C, and by CICYT, Spain, under grant MAT92-32. The author gratefully acknowledges the assistance of Prof. M. Elices, Dr. A. Martín, Dr. J. Ruiz, Mr. I. Arbilla, and Mr. P. Poza during the course of this work. The micrographs in Fig. 1 were kindly provided by Dr. D. L. Zhang and Dr. B. Cantor from Oxford University.

\section{REFERENCES}

[1] NAKAGAWA, A. H., and GUNGOR, M. N., Fundamental Relationships Between Microstructures and Mechanical Properties of Metal Matrix Composites, M. N. Gungor and P. K. Liaw, eds., TMS, Pennsylvania, U. S. A., (1990) 127.

[2] LEWANDOWSKI, J. J., LIU, C., and HUNT, W. H., Mater. Sci. Engng. A107 (1989) 241.

[3] LLORCA, J., MARTIN, A., RUIZ, J., and ELICES, M., Metall. Trans. 24A (1993). In press.

[4] LLOYD, D. J., Acta Metall. Mater, 39 (1991) 59.

[5] BRECHET, Y., EMBURY, J. D., TAO, S., and LUO, L., Acta Metall. Mater. 39 (1991) 1781.

[6] MOCHIDA, T., TAYA, M., and LLOYD, D. J., Mater. Trans. JIM 32 (1991) 931.

[7] LLORCA, J., SURESH, S., and NEEDLEMAN, A., Metall. Trans. 23A (1992) 919.

[8] McDANELS, D. L., Metall. Trans. 16A (1985) 1105.

[9] NUTT, S. R., Scripta Metall. 21 (1987) 705.

[10] KIM, H. J., KOBAYASHI, T., YOON, H. S., and YOON, E. P., Mater. Sci. Engng. A154 (1992) 35.

[11] KAMAT, S. V., HIRTH, J. P., and MEHRABIAN, R., Acta Metall. 37 (1989) 2395. 